\title{
Proposing a cross-cultural peer support programme to enhance Chinese direct entry students' academic performance and learning experience
}

\author{
Xiaowen Gao \\ University of Greenwich
}

Keywords: Cross-cultural peer learning, personalised learning, Chinese direct entry students, Business education

Since the recognition that personalised higher education (HE) learning experiences enhance student satisfaction and retention (Keenan 2014), the number of United Kingdom (UK) universities implementing peer support programmes to facilitate personalised learning has been growing rapidly. Personalised learning is learner-centred learning, tailored to an individual's learning needs, abilities and goals (Becket and Brookes, 2012). The adoption of peer-assisted learning (PAL) has been proved to be successful in personalising students' learning experiences and promoting students as active partners in their learning (HEA, 2014). These positive outcomes should encourage us to consider a design which is more culturally inclusive in order to benefit international students.

Continuing innovation undertaken in HE in the UK has always attracted a growing number of international students to study in UK universities. In particular, the number of Chinese students is up by $43 \%$ since $2011-2012$ (Bolton, 2019). This year alone, applications from China have increased by thirty per cent (Weale, 2019). International students are important stakeholders of higher education institutions (HEIs) in the UK, their contributions to universities extending beyond the revenue they bring to the international profile of the hosting universities and the strategic alliances with other nations (Alfattal 2016). Needless to say, the learning experience and satisfaction of international students are of importance for universities. However, the support for international students' personalised learning is lacking in UK HEls.

It is claimed by Bond and Scudamore (2010) that learners from various cultures learn differently, affected by a range of factors including educational experience, age, gender and social status. It is unrealistic to expect formal learning to accommodate the learning needs of each individual student. Therefore, PAL could play a significant role in accommodating students' personalised learning experience.

PAL is not a replacement for professional teaching conducted by lecturers but supplementary learning allowing students to learn in a student community which represents a safe place for them to ask questions and gain confidence (Herrmann-Werner et al., 2017). Since active support among status equals leads to the acquisition of knowledge and skills (Topping 2001), it offers academics opportunities to engage and work in partnership with students to enhance their personalised learning experience, ensure their retention and enhance their satisfaction. 
Becoming a PAL leader is voluntary for experienced students; leaders are awarded points linked to the university's employability development reward scheme. Students participating in PAL schemes have described their experience: "rewarding"; "not only gaining real-life transferable skills but also the satisfaction of having an impact on someone else's university life" (University of Reading); "settled into the course more quickly"; "really useful and enjoyed the sessions" (University of Brighton).

PAL programmes have also been highly commended by academic staff from various universities, as they not only result in a higher level of student engagement, but also create both links between year groups and student partnerships with academic and administrative staff (Ody and Carey, 2009).

Chinese direct entry (DE) students would particularly benefit from PAL for two reasons: First, they have been commonly characterised as 'silent', 'collective' learners (Bond and Scudamore, 2010) who have high respect for lecturers in formal learning but are not very verbally responsive to classroom teaching. Peer-to-peer assisted learning would therefore be more effective when they learn from peers in an informal environment. Second, there is a lack of collaborative learning between Chinese DE students and other student groups on UK university campuses. Chinese students often exclude themselves from other student groups owing to weak language skills. They may also be regarded by other student groups as too exclusive, only talking to and being friendly with fellow Chinese students. A cross-cultural peer-to-peer assisted learning programme would mutually enhance students' international experience by enabling learning from each other. A cross-cultural PAL could build a bridge between Chinese students and students from different cultures to the benefit of all, academically and culturally.

Currently, little attention has been paid to PAL programmes aimed at supporting international students' personalised learning on UK-based campuses. Only one trial targeting Chinese students was reported in the Higher Education Academy's 2014 report - it was carried out in China by a small number of second-year students from the University of Leeds during their trip to China (Keenan, 2014).

Although it is important to implement a cross-culture PAL scheme, some potential challenges need to be considered beforehand. First, when students learn from each other in an informal environment, it is important to make sure that the learning is well structured. Second, students need to be motivated to learn from one another - participating in peerlearning without motivation would result only in reduced time for independent learning, with possible adverse impact on academic performance. Third, there are cost implications in setting up the programme and providing training to students.

In conclusion, international students' satisfaction is essential for universities, which can benefit from offering opportunities on personalised learning. Despite the challenges mentioned above, we believe peer-to-peer cross culture PAL could be an effective approach to providing personalised learning for international students. We therefore propose that such peer learning should be initiated at the University of Greenwich Business Faculty and, indeed, all business schools in the UK. 


\section{Reference list}

Alfattal, E. (2016) 'A New Conceptual Model for Understanding International Students' College Needs.' Journal of International Students, 6(4). Available at:

https://files.eric.ed.gov/fulltext/EJ1125549.pdf (Accessed: 11 September 2019).

Becket, N. and Brookes, M. (2012) 'The potential benefits and challenges of personalising UK higher education.' Journal of Hospitality, Leisure, Sports \& Tourism Education, 11, 21-28. Available at: https://www.sciencedirect.com/science/article/abs/pii/S1473837612000056 (Accessed: 15 September 2019).

Bolton, P. (2019) 'Higher education students numbers.' Briefing Paper. Available at: https://researchbriefings.parliament.uk/ResearchBriefing/Summary/CBP-7857 (Accessed: 15 November 2019).

Bond, K. and Scudamore, R. (2010) Woking with International Students: a Guide for Staff in Engineering. York: Higher Education Academy. Available at: https://www.heacademy.ac.uk/system/files/working-with-international-students.pdf (Accessed: 12 September 2019).

Herrmann-Werner, A. and Gramer, R. (2017) 'Peer assisted learning in undergraduate education: An overview.' ZEFQ. Available at:

https://www.ncbi.nlm.nih.gov/pubmed/28545616 (Accessed: 14 September 2019).

Keenan, C. (2014). 'Mapping student-led peer learning in the UK.' The Higher Education Academy. Available at:

https://www.advance-he.ac.uk/knowledge-hub/mapping-student-led-peer-learning-uk (Accessed: 11 September 2019).

Topping, K., (2001) 'Peer Assisted Learning: A Practical Guide for Teachers', Cambridge, MA: Brookline Books. ISBN 978-1571290854.

Weale, S. (2019) 'Chinese students' applications to UK universities up by $30 \%$.' The Guardian. Available at:

https://www.theguardian.com/education/2019/jul/11/chinese-students-applications-to-ukuniversities-up-by-30 (Accessed: 9 September 2019). 